\title{
Optimum Conditions of UV Ray Irradiation for Genetic Inactivation of Loach Eggs ${ }^{* 1}$
}

\author{
Katsutoshi Arai, ${ }^{* 2}$ Tetsuji Masaoka, ${ }^{* 2}$ and Ryo Suzuki*2 \\ (Received July 6, 1991)
}

\begin{abstract}
Optimum conditions of ultraviolet (UV) ray irradiation for genetic inactivation of eggs were examined to develop simple and easy techniques to induce androgenesis in the loach, Misgurnus anguillicaudatus, since ionizing radiation such as gamma- or X-ray, which has been used generally for fish androgenesis, gives technical problems of safety and the need for special facilities. In the first and second experiments, unfertilized eggs were exposed to UV rays from two sources, germicidal lamps affixed to the ceiling and below, at dosages from 1875 to $15000 \mathrm{erg} / \mathrm{mm}^{2}$. While in the third experiment, eggs being shaken in a micro mixer were irradiated with UV rays from ceiling lamps at dosages between 4200 and $21000 \mathrm{erg} / \mathrm{mm}^{2}$. Most embryos developing after fertilization with normal spermatozoa showed abnormal morphology and a haploid number of chromosomes $(n=25)$ in all the experiments, indicating successful induction of androgenesis. Occurrence of some aneuploids and diploids suggests the necessity of further improvement for homogeneity of treatment.
\end{abstract}

Androgenetic development (all paternal inheritance) in fish can be triggered by fertilizing gamma- or X-ray irradiated eggs with normal spermatozoa, but the resultant embryos show inviable abnormality due to haploidy. ${ }^{1-5}$ Viable diploid androgenomes were produced in salmonids by doubling the paternal chromosome set through suppression of the first cleavage using hydrostatic pressure treatment ${ }^{8-8)}$ or by inseminating genetically inactivated eggs with diploid spermatozoa from induced tetraploid males. ${ }^{9)}$ The applicable potential of androgenesis involves the rapid establishment of an inbred line, sex control using anticipated super male (YY) in the male heterogametic species, production of a nucleo-cytoplasmic hydrid between different species, and the recovery of valuable strains or species from cryopreserved spermatozoa. However, much less work has been done to develop techniques for inducing androgenetic fish, because the inactivation of egg nucleus in fish with ionizing radiation such as gamma- or X-rays gives technical difficulty including problems of safety as well as facilities for managing the radioactive source. On the contrary, ultraviolet (UV) rays are used routinely and widely to inactivate spermatozoa for easy induction of gynogenesis in various species of fish, ${ }^{10-12}$ ) after the successful development of efficient methods for irradiation to overcome the weak penetrating power of UV rays. ${ }^{13,14)}$ A few attempts at UV inactivation of eggs have been reported in fancy carp Cyprinus carpio ${ }^{15,18)}$ but the optimum conditions of UV irradiation were inconclusive because of the low and unstable occurrence of androgenomes. In the present study, we examine the optimum conditions of UV ray irradiation of eggs in order to develop a simple and safe method for inducing androgenetic development in the loach Misgurnus anguillicaudatus.

\section{Materials and Methods}

\section{Loach Specimens}

Specimens were obtained from the Misakagawa River, Hiroshima Prefecture, and from a dealer in Mie Prefecture. Ploidy of these specimens was determined as diploidy, on the basis of erythrocyte measurements. ${ }^{17)}$ Ripe eggs were hand-stripped $10-15 \mathrm{~h}$ after injection with human chorionic gonadotropin (HCG). Spermatozoa were diluted to a concentration of $10^{-2}$ with M/7.5 Ringer's solution adjusted to $\mathrm{pH} 7.8$. Each androgenetic experiment was made using eggs from one female and mixed spermatozoa from four males.

*1 Supported in part by the Grant-in-Aid for scientific research (no. 02454080) from the Ministry of Education, Science, and Culture, Japan.

*2 Faculty of Applied Biological Science, Hiroshima University, Kagamiyama, Highashi-hiroshima, Hiroshima 724, Japan (筧井克俊, 正岡哲治, 鈴木 克: 広島大学生物生産学部). 


\section{UV Irradiation of Eggs}

UV ray irradiation was performed in a box (approximately $700 \mathrm{~mm}$ high, $480 \mathrm{~mm}$ wide, and $350 \mathrm{~mm}$ deep) using germicidal lamps GL-15W (Toshiba Co. Ltd), commercially available, affixed to both the ceiling and the bottom of the box. In the first and second experiment, eggs were placed on a plastic dish $(50 \mathrm{~mm}$ diameter and $10 \mathrm{~mm}$ deep) with a sheet of almost transparent cellophane film at the bottom. The dish containing about 200 to 460 egg specimens suspended in about $1.5 \mathrm{ml}$ of Ringer's solution was covered with the cellophane film and then was set up on the stand, installed exactly between the ceiling-lamps and the bottom-lamps $(350 \mathrm{~mm}$ distant from each UV source). The lamp was warmed up for stabilization before starting irradiation. Each dish was exposed to UV rays from both sides (ceiling and bottom) for varying durations of irradiation at $125 \mathrm{erg} / \mathrm{mm}^{2} / \mathrm{s}$ from 15 to $120 \mathrm{~s}$. The final UV dosages against egg specimens were $1875,3750,7500,11250$, and $15000 \mathrm{erg} / \mathrm{mm}^{2}$ for the first experiment and 3750 , 7500 , and $11250 \mathrm{erg} / \mathrm{mm}^{2}$ for the second experiment.

In the third experiment, a different method of UV irradiation was used. A petri dish $(90 \mathrm{~mm}$ diameter and $10 \mathrm{~mm}$ deep) containing egg specimens and $10 \mathrm{~m} l$ of Ringer's solution was placed on a micro mixer (Taiyo Co. Ltd.) which made the treatment homogeneous by shaking. The distance between the ceiling-lamps and the specimens was $420 \mathrm{~mm}$. Each dish was exposed to UV rays from the two lamps affixed to the ceiling of the box for varying durations of irradiation at $70 \mathrm{erg} / \mathrm{mm}^{2} / \mathrm{s}$ from 60 to $300 \mathrm{~s}$, giving final UV dosages of $4200,8400,12600,16800$ and $21000 \mathrm{erg} / \mathrm{mm}^{2}$.

\section{Fertilization and Rearing of Embryos}

After UV irradiation, eggs were mixed with normal spermatozoa and then immersed in freshwater. Fertilized eggs of each batch were kept and reared in freshwater in a container $(270 \mathrm{~mm}$ long, $200 \mathrm{~mm}$ wide and $40 \mathrm{~mm}$ deep). The percentage of eggs which hatched and that of deformed fry were recorded. Typical fry from the control and the irradiated batch were photographed.

\section{Chromosome Preparation}

About $18 \mathrm{~h}$ after fertilization. randomly selected developing eggs were dechorionized by treating with $2 \%$ trypsin dissolved in Ringer's solution (pH 9.0) for 10-15 min, and then treated with $0.5 \%$ colchicine for $2.5 \mathrm{~h}$. They were treated with $0.075 \mathrm{~mol} \mathrm{KCl}$ for $25 \mathrm{~min}$ and fixed with 3 ethanol: 1 acetic acid mixture. Chromosome slides were prepared according to the procedure prposed by Yamazaki et al. ${ }^{18)}$

Table 1. Rates of hatched and deformed fry and ploidy status of embryos developing after UV irradiation of eggs

\begin{tabular}{|c|c|c|c|c|c|c|c|c|}
\hline \multirow{2}{*}{$\begin{array}{l}\text { Exp. } \\
\text { no. }\end{array}$} & \multirow{2}{*}{$\begin{array}{c}\text { UV } \\
\text { dodage } \\
\text { (erg/mm²) }\end{array}$} & \multirow{2}{*}{$\begin{array}{l}\text { No. of } \\
\text { eggs } \\
\text { used }\end{array}$} & \multirow{2}{*}{$\begin{array}{c}\text { Hatched } \\
\text { fry } \\
(\%)\end{array}$} & \multirow{2}{*}{$\begin{array}{c}\text { Deformed } \\
\text { fry } \\
(\%)\end{array}$} & \multicolumn{4}{|c|}{ Ploidy } \\
\hline & & & & & Total*2 & $2 n^{* 3}$ & Aneuploid*4 & $n^{* 5}$ \\
\hline \multirow[t]{6}{*}{1} & $0^{* 1}$ & 282 & 36.9 & 1.0 & - & - & - & - \\
\hline & 1875 & 203 & 44.8 & 84.6 & 4 & 0 & 0 & 4 \\
\hline & 3750 & 226 & 35.0 & 94.9 & 11 & 0 & 2 & 9 \\
\hline & 7500 & 278 & 39.6 & 90.9 & 7 & 0 & 3 & 4 \\
\hline & 11250 & 270 & 23.7 & 98.3 & 8 & 0 & 2 & 6 \\
\hline & 15000 & 225 & 7.1 & 94.3 & 9 & 0 & 1 & 8 \\
\hline \multirow[t]{4}{*}{2} & 0 & 183 & 66.7 & 0 & 5 & 5 & 0 & 0 \\
\hline & 3750 & 221 & 47.1 & 94.3 & 12 & 0 & 1 & 11 \\
\hline & 7500 & 265 & 23.0 & 96.3 & 11 & 0 & 0 & 11 \\
\hline & 11250 & 464 & 16.6 & 100 & 6 & 0 & 1 & 5 \\
\hline \multirow[t]{6}{*}{3} & 0 & 141 & 31.2 & 0 & 4 & 4 & 0 & 0 \\
\hline & 4200 & 301 & 24.3 & 93.0 & 6 & 0 & 1 & 5 \\
\hline & 8400 & 187 & 33.7 & 92.0 & 7 & 0 & 0 & 7 \\
\hline & 12600 & 386 & 17.9 & 97.2 & 10 & 2 & 1 & 7 \\
\hline & 16800 & 159 & 3.8 & 100 & 3 & 0 & 1 & 2 \\
\hline & 21000 & 263 & 22.1 & 100 & 7 & 2 & 0 & 5 \\
\hline
\end{tabular}

*1, non-irradiated control; *2, total number of embryos examined; *3, diploid $(2 \mathrm{n}=50) ; * 4$, near haploid with maternally derived chromosome(s) and/or chromosome fragment $(s) ; * 5$, haploid $(n-25)$. 


\section{Results}

The hatching rates of the irradiated batches tended to decrease, depending on the increase of UV dosage on specimens in all the experiments, and were markedly lower than that of the control in the batches irradiated at above $11250 \mathrm{erg} / \mathrm{mm}^{2}$ in the first and second experiment and at above $12600 \mathrm{erg} / \mathrm{mm}^{2}$ in the third experiment (Table 1). More than $90 \%$ of hatched fry showed deformity in all batches even with $3750 \mathrm{erg} / \mathrm{mm}^{2}$ irradiation (Table 1). The appearance of the deformed fry (Fig. 1) was similar to that of haploid embryos described by Suzuki et al. ${ }^{19}$ )

Results of chromosome counts showed that most embryos from UV irradiated eggs were haploidy with 25 chromosomes, while all control embryos examined had diploidy with 50 chromosomes (Table 1, Fig. 2a, b). However, aneuploidy with supernumerary and/or fragmented chromosome (s), which are probably residues of

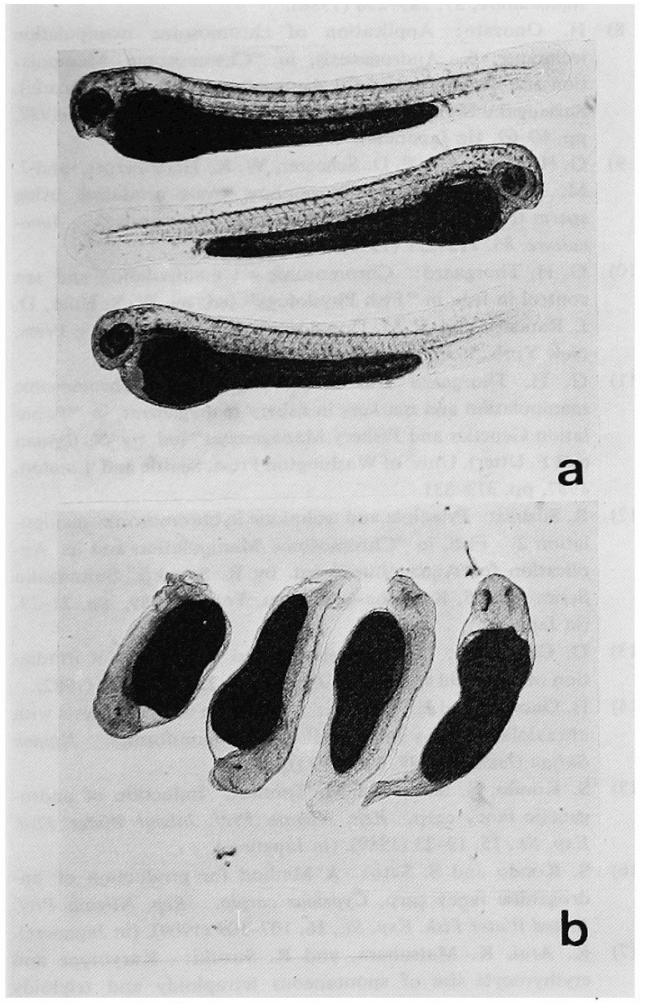

Fig. 1. External appearance of normal fry (a) and deformed fry (b), developing from the control and the UV irradiated batch, respectively. the maternal nucleus, were observed in some specimens from a low dose to a high dose of UV irradiation (Fig. 2c). No diploid embryos were detected in the first or second experiments but some in the third, in which the irradiating procedure was different from the former two experiments.

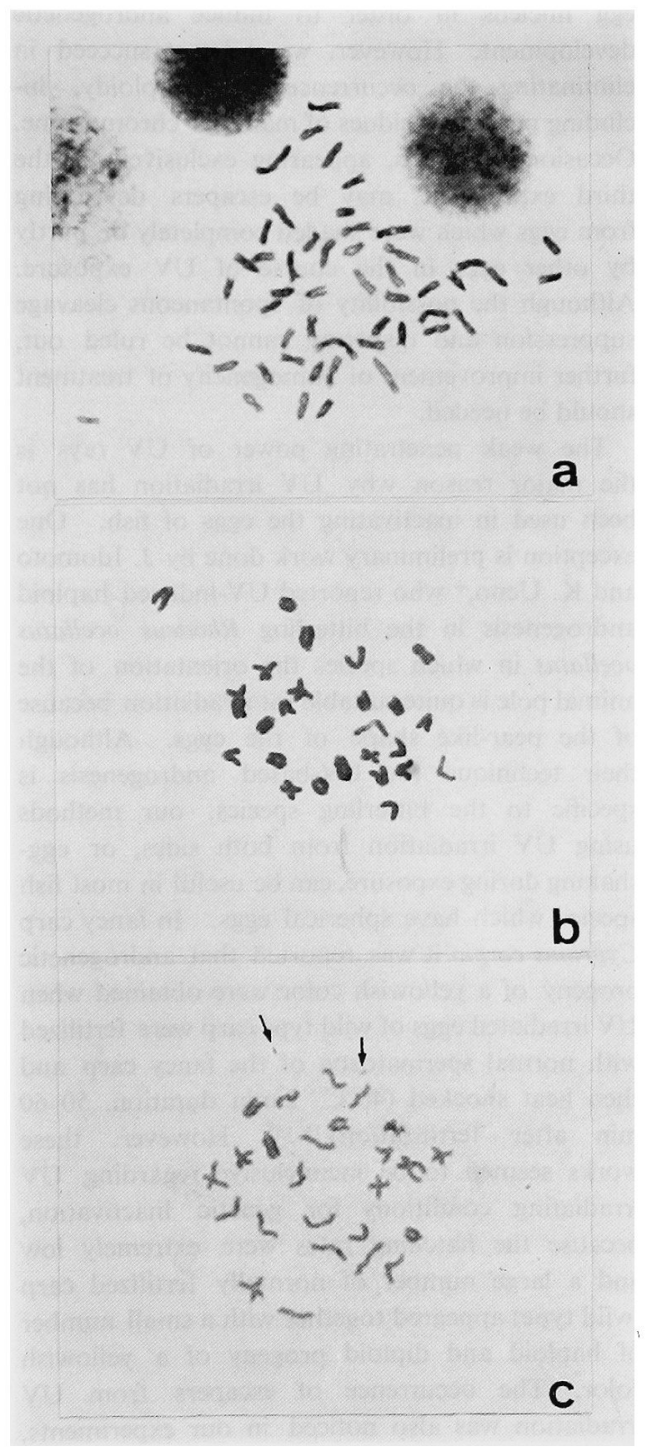

Fig. 2. Metaphase spreads of normal diploid with 50 chromosomes (a), androgenetic haploid with 25 chromosomes (b), and aneuploid with supernumerary chromosome fragments of possibly maternal origin (c). Arrow indicates chromosome fragment. 


\section{Discussion}

Abnormal embryos developing from UV irradiated eggs are proved to be primarily haploidy, on the basis of chromosome observations. The results demonstrate that the two simple procedures of UV irradiation used in the present study effectively inactivate genetic materials of the egg nucleus in order to induce androgenetic development. However, we did not succeed in eliminating the occurrence of aneuploidy, including possible residues of maternal chromosome. Occasional diploids, appearing exclusively in the third experiment, may be escapers developing from eggs which were shaded completely or partly by other eggs in the course of UV exposure. Although the possibility of spontaneous cleavage suppression and dispermy cannot be ruled out, further improvement of homogeneity of treatment should be needed.

The weak penetrating power of UV rays is the major reason why UV irradiation has not been used in inactivating the eggs of fish. One exception is preliminary work done by J. Idomoto and $\mathrm{K}$. Ueno, ${ }^{*}$ who reported $\mathrm{UV}$-induced haploid androgenesis in the bitterling Rhodeus ocellatus ocellatus in which species the orientation of the animal pole is quite suitable for irradiation because of the pear-like shape of the eggs. Although their technique for UV-based androgenesis is specific to the bitterling species, our methods using UV irradiation from both sides, or eggshaking during exposure, can be useful in most fish species which have spherical eggs. In fancy carp Cyprinus carpio it was reported that androgenetic progeny of a yellowish color were obtained when UV irradiated eggs of wild type carp were fertilized with normal spermatozoa of the fancy carp and then heat shocked $\left(40^{\circ} \mathrm{C}, 2 \mathrm{~min}\right.$ duration, $50-60$ min after fertilization). ${ }^{15,10)}$ However. these works seemed to be inconclusive regarding UV irradiating conditions for genetic inactivation, because the hatching rates were extremely low and a large number of normally fertilized carp (wild type) appeared together with a small number of haploid and diploid progeny of a yellowish color. The occurrence of escapers from UV irradiation was also noticed in our experiments, but we succeeded in producing more than $90 \%$ of androgenetic haploidy even after $3750 \mathrm{erg} / \mathrm{mm}^{2}$ irradiation.

Diploidization of androgenomes is the next step for the application of androgenesis in aquaculture. Suppression of the first cleavage for duplication of paternal chromosomes is now underway in our laboratory.

\section{References}

1) D. D. Romashov and V. V. Belyaeva: The cytology of the radiation gynogenesis and androgenesis in the loach (Misgurnus fossilis). Dokl. Acad. Nauk. SSSR, 157, 964-967 (1964).

2) C. E. Purdom: Radiation-induced gynogenesis and androgenesis in fish. Heredity, 24, 431-444 (1969).

3) K. Arai, H. Onozato, and F. Yamazaki: Artificial androgenesis induced with gamma irradiation in masu salmon, Oncorhynchus masou. Bull. Fac. Fish. Hokkaido Univ., 30 , 181-186 (1979).

4) J. E. Parsons and G. H. Thorgaard: Induced androgenesis in rainbow trout. J. Exp. Zool., 231, 407-412 (1984).

5) B. May, K. J. Henley, C. C. Krueger, and S. P. Gloss: An* drogenesis as a mechanism for chromosome set manipulation in brook trout (Salvelinus fontinalis). Aquaculture, 75, 57-70 (1988).

6) J. E. Parsons and G. H. Thorgaard: Production of androgenetic diploid rainbow trout. $J$. Heredity, 76, 171-181 (1985).

7) P. D. Scheerer, G. H. Thorgaard, F. W. Allendorf, and K. L. Knudsen: Androgenetic rainbow trout produced from inbred and outbred sperm sources show similar survival. Aquaculture, 57, 289- 298 (1986).

8) H. Onozato: Application of chromosome manipulation technique, 6. Androgenesis, in "Chromosome Manipulation and its Application for Aquaculture" (ed. by R. Suzuki), Suisangaku Series vol. 75, Koseisha-koseikaku, Tokyo, 1989, pp. 60 69. (in Japanese).

9) G. H. Thorgaard, P. D. Scheerer, W. K. Hershberger, and J. M. Myers: Androgenetic rainbow trout produced using sperm from tetraploid male show improved survival. Aquaculture, 85, 215-221 (1990).

10) G. H. Thorgaard: Chromosome set manipulation and sex control in fish, in "Fish Physiology" (ed. by W. S. Hoar, D. 3. Randall, and E. M. Donaldson), Vol. 9, Academic Press, New York, 1983, pp. 405-434.

11) G. H. Thorgaard and S. K, Allen, Jr.: Chromosome manipulation and markers in fishery management, in "Population Genetics and Fishery Management" (ed. by N. Ryman and F. Utter), Univ, of Washington Press, Seattle and London, 1987, pp. 319-331.

12) R. Suzuki: Principle and technique in chromosome manipulation 2. Fish, in "Chromosome Manipulation and its Application for Aquaculture" (ed. by R. Suzuki), Suisangaku Series vol. 75, Koseisha-koseikaku, Tokyo, 1989, pp. 21-29. (in Japanese).

13) D. Chourrout: Gynogenesis caused by ultraviolet irradiation of salmonid sperm. J. Exp. Zool, 223, 175-181 (1982).

14) H. Onozato and E. Yamaha: Induction of gynogenesis with ultraviolet rays in four species of salmoniformes. Nippon Suisan Gakkaishi, 49, 693-699 (1983).

15) S. Kondo, S. Sato, and $M$. Tomita: Induction of androgenetic fancy carp. Rep. Nigata Pref. Inland Water Fish. Exp. St., 15, 19-23 (1989). (in Japanese).

16) S. Kondo and S. Sato: A Method for production of androgenitic fancy carp, Cyprinus carpio. Rep. Nigata Pref. Inland Water Fish. Exp. St, 16, 107-109 (1909). (in Japanese).

17) K. Arai, K. Matsubara, and R. Suzuki: Karyotype and erythyrocyte size of spontaneous tetraploidy and triploidy in the loach, Misgurnus anguillicaudatus. Nippon Suisan Gakkaishi, 57, 2167-2172 (1991).

\footnotetext{
* Abstract. Annu. Meet. Jpn. Soc. Sci. Fish. April, 1987. Tokyo, p. 152 (in Japanese).
} 
18) F. Yamazaki, H. Onozato, and K. Arai: The chopping method for obtaining permanent chromosome preparation from embryos of teleost fish, Nippon Suisan Gakkaishi, 47, 963 (1981).
19) R. Suzuki, T. Oshiro, and T. Nakanishi: Survival, 'growth and fertility of gynogenetic diploids induced in the cyprinid loach, Misgurnus anguillicaudatus. Aquaculture, 48, 45-55 (1985). 